\title{
OBSERVATIONS ON THE PYROGENIC RESPONSE AND ITS APPLICATION TO THE BIOASSAY OF ENDOTOXIN
}

\author{
By WILLIS R. KEENE,* HAROLD R. SILBERMAN † AND MAURICE LANDY with \\ THE ASSISTANCE OF KATHERINE A. STRELECKY
}

(From the Laboratory of Chemical Pharmacology, National Cancer Institute, Bethesda, Md.)

(Submitted for publication July 27, 1960; accepted September 30, 1960)

Endotoxins prepared from gram-negative bacteria produce a wide variety of physiological reactions when administered to man and experimental animals. The intravenous injection of microgram quantities of these lipopolysaccharides into the appropriate host is followed by fever, leukopenia, thrombocytopenia, hyperglycemia, and irreversible shock. In addition, endotoxins are capable of producing the Shwartzman phenomenon, dermal necrosis, renal cortical necrosis, and hemorrhagic necrosis of certain tumors (1).

The ubiquity of endotoxins has necessitated routine screening of all fluids and medications prepared for parenteral therapy, for which the pyrogenic response of the rabbit is commonly used. However, there have been few systematic studies of the dose-pyrogenic response relationships and little is known concerning the relative susceptibilities of rabbit and man to the pyrogenic and toxic properties of endotoxin (2-5).

In this report the dose-febrile response curve for Serratia marcescens endotoxin is described. Data are also presented which show the relative susceptibilities of several species, including man, to the pyrogenic properties of endotoxin. An analysis of the data from an extensive series of experiments demonstrates that the febrile reaction of the rabbit provides a consistent and objective procedure for the bioassay of endotoxins.

\section{Endotoxin}

\section{METHOD}

All experiments, except where otherwise stated, were done with a single endotoxin prepared by Perrault and Shear (6) from Serratia marcescens (lot P-45). Serratia endotoxin, prepared in this manner, has been characterized by Rathgeb and Sylvén (7) as a phospholipid-polysaccharide-protein complex in which the nitrogen con-

* Present address: U. S. Public Health Service Hospital, Boston, Mass.

† Present address: Duke University Hospital, Durham, tent was 1.8 per cent and the carbohydrate moiety represented 76 per cent of the total dry weight.

\section{Animals}

Rabbits. All animals were New Zealand white rabbits of both sexes, weighing 2 to $3 \mathrm{~kg}$, bred at the Animal Production Unit, National Institutes of Health. Prior to pyrogen tests the rabbits were trained in wooden stocks, with loosely fitting collars as the only restraining device. Before the injection was given, 1 hour was allowed for further acclimatization to the stocks. Only animals with baseline temperatures between $38.5^{\circ}$ and $39.9^{\circ} \mathrm{C}$ were used for pyrogen assay. When individual rabbits were used more than once, a 2 week period was allowed between tests to avoid pyrogen tolerance.

Cats. These were of mixed breeds and weighed 2.0 to $2.4 \mathrm{~kg}$. They were kept in the laboratory for 1 week prior to use and were trained in the wooden stocks just as were the rabbits. They adapted rapidly to the restraining device and had very stable baseline temperatures.

Horses. Doses of endotoxin near the pyrogenic threshold were administered to one $500 \mathrm{~kg}$ female and one 300 $\mathrm{kg}$ male. Each horse was injected twice, with an 8 week rest period between injections.

Dogs. Beagle hounds of both sexes were obtained from local breeders. The weights ranged from 9 to 11 kg. All were docile and minimal restraint was required for injections or the recording of temperatures.

Chimpanzees. Two animals housed at the Walter Reed Army Institute of Medical Research were trained over a 2 week period. At the time of the experiment they tolerated, without restraint, temperature recording with a clinical thermometer. Both were females, weighing 12.7 and $14.5 \mathrm{~kg}$, and neither had been used in other experiments for 18 months prior to the administration of endotoxin. ${ }^{1}$

\section{Patients}

Six patients hospitalized on the general medical service of the National Cancer Institute participated in this study. The malignancies represented among the patients included malignant melanoma, bronchogenic carcinoma, mycosis fungoides, and gastric carcinoma. None of the patients had overt evidence of liver disease, although one patient did have an elevated alkaline phosphatase and he-

1 The authors are indebted to Lt. Col. S. Gaines for providing these animals. 
patic metastases may have been present. There were 2 females and 4 males; the weights ranged from 52 to 65 $\mathrm{kg}$.

\section{Recording of temperature}

The temperatures were recorded rectally and the pyrogen tests were always conducted in a room with the same ambient temperature as that of the animal housing areas. Temperatures of rabbits, cats and horses were recorded by the use of rectal resistance coils (Telethermometer, Yellow Springs Instrument Co.), which were inserted to a depth of 4 inches or more. The rectal temperatures of the dog and chimpanzee were recorded with clinical thermometers. These two species remained free in their cages throughout the experiments. Patient temperatures were recorded at 4-minute intervals using rectal thermo-couples and an automatic multipoint recorder (Minneapolis Honeywell). Temperatures were measured immediately before injection and at 30-minute intervals thereafter until they returned to normal.

\section{Fever index}

Febrile responses were plotted on $1 \times 1$ inch standard graph paper (K. \& E., 353-10) with $1^{\circ} \mathrm{C}$ and 1 hour equaling 1 inch. The area under the curve was measured in square centimeters with a compensating polar planimeter (K. \& E., no. $4236 \mathrm{M}$ ). The fever index thus represents a measure of the height and duration of the febrile response (8). Certain difficulties in computing the fever index are noteworthy. The diurnal variation of normal body temperature in man was so great that temperatures seldom returned to pre-injection values. In such instances the fever curve was extrapolated to the baseline. Likewise, the body temperature of 5 to 10 per cent of the rabbits used in these experiments leveled off at 0.5 to $1.0^{\circ} \mathrm{C}$ above the pre-injection value. These curves, too, were extrapolated to the baseline. No difficulty was encountered in measuring the fever index for the horse and cat because the temperature of these animals always returned to pre-injection values.

\section{Avoidance of contamination by bacterial pyrogens}

Glassware, needles and syringes were baked overnight in a hot air oven at 150 to $160^{\circ} \mathrm{C}$ to eliminate pyrogens. Sterile, nonpyrogenic, physiological saline (Baxter Laboratories, Inc.) was used as diluent for endotoxin. It was checked periodically and was always found to be pyrogen-free.

Injections

All injections were made intravenously. Rabbits were injected into the marginal ear vein, horses into the jugular vein, cats and dogs into the cephalic vein and the chimpanzees and patients were injected into the antecubital vein. The volume of each injection was $1 \mathrm{ml}$.

\section{EXPERIMENTAL}

Dose-febrile response relationships. Measurements were made of the febrile response of the rabbit to a series of graded doses of endotoxin ranging from minimally pyrogenic to near-lethal. For the Serr. marcescens endotoxin this range was found to be 0.1 to $100 \mu \mathrm{g}$ per animal. The number of animals tested for each dose was :

$$
\begin{array}{lccccrccc}
\text { Dose }(\mu \mathrm{g}) & 0.1 & 0.5 & 1 & 2 & 5 & 10 & 20 & 100 \\
\text { Number } & 8 & 6 & 8 & 4 & 15 & 15 & 12 & 6
\end{array}
$$

As illustrated in Figure 1, the extremes of the dose-response curve were relatively flat; however, in the range of 1 to $20 \mu \mathrm{g}$ per animal, the ratio of dose to febrile response was constant. A similar dose-response curve was obtained with another endotoxin, which was derived from Salmonella typhosa 0901 (9). It is noteworthy that the doseresponse ratios for both endotoxins were constant only for doses that produced biphasic febrile responses.

Measurements of pyrogenic potency. The minimal pyrogenic dose has been frequently used to compare the pyrogenic potencies of different endotoxin preparations. However, inspection of the dose-response curve makes it clear that more precise comparisons would be expected if the amount of endotoxin were sufficient to produce febrile responses that fell on the linear portion of the curve. Dose-febrile response ratios were determined for three endotoxins ; potency was calculated from these data by two methods: 1) minimal dose required to produce $0.6^{\circ} \mathrm{C}$ rise (Figure 2) ; and 2) minimal dose necessary to produce a fever

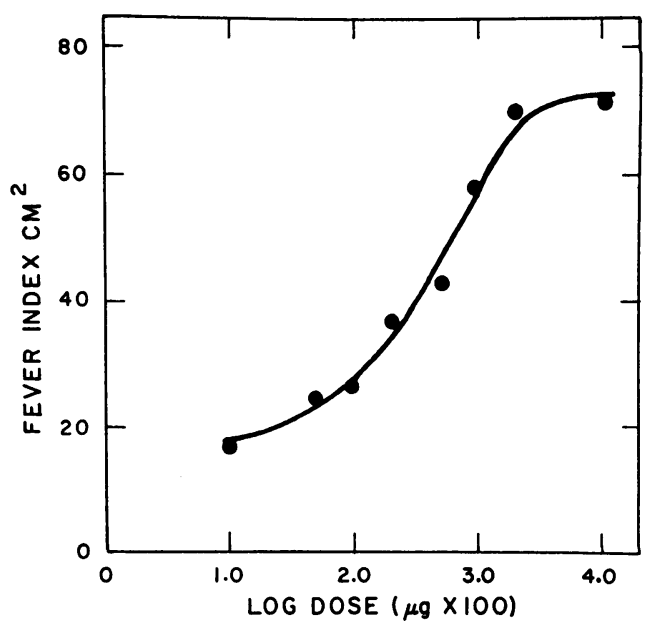

Fig. 1. LOG DOSE-FEBRILE RESPONSE CURVE OF NORMAL RABBITS to SERR. MARCESCENS ENDOTOXIN. Each point represents the mean fever index of 4 to 15 animals. 


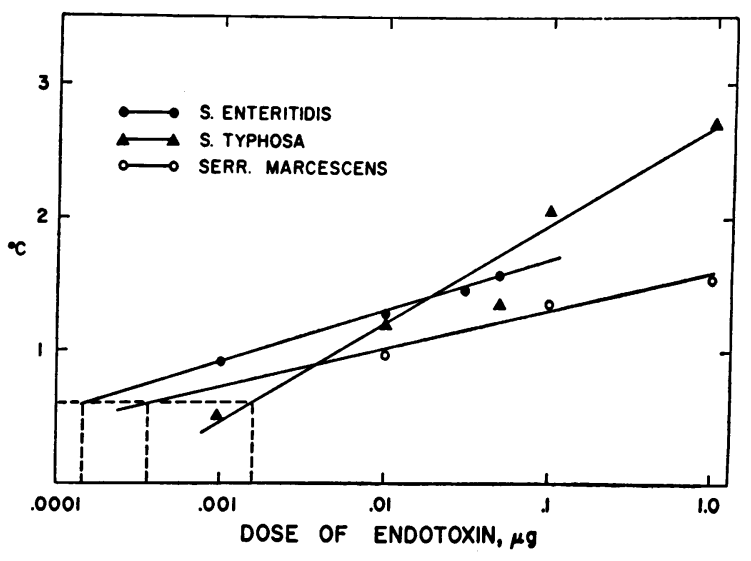

Fig. 2. DOSE-FEbRILE RESPONSE CURVES FOR THREE ENDotoxins. The minimal dose necessary to produce $0.6^{\circ} \mathrm{C}$ rise in body temperature was calculated as illustrated.

index of $40 \mathrm{~cm}^{2}$, which falls on the linear portion of the dose-response curve.

It is evident from the data in Table I that the two methods of comparing pyrogenic potency yielded grossly different results. For example, when the minimal pyrogenic dose was used it appeared that Salmonella enteritidis endotoxin was three times as pyrogenic as Serr. marcescens. However, when doses necessary to produce a fever index of $40 \mathrm{~cm}^{2}$ were compared, it was evident that the endotoxin from $S$. enteritidis was at least 48 times as pyrogenic as the Serr. marcescens endotoxin. The configuration of the doseresponse curve indicates that the latter value may be a more reliable measure of over-all pyrogenic effect.

Distribution of fever indices. It is now well known that variability in the pyrogenic response of the rabbit can be significantly reduced by observing the following precautions: 1) use of minimal restraint during the assay, preferably a loosely

TABLE I

Comparison of minimal pyrogenic dose and fever index as measures of endotoxin potency

\begin{tabular}{lcc}
\hline $\begin{array}{c}\text { Microbial origin } \\
\text { of endotoxin }\end{array}$ & $\begin{array}{c}\mathbf{0 . 6}{ }^{\circ} \mathrm{C} \\
\text { rise }\end{array}$ & $\begin{array}{c}\text { Fever index } \\
\mathbf{4 0 \mathrm { cm } ^ { 2 }}\end{array}$ \\
& $\mu \mathrm{g} / \mathrm{kg}$ & $\mu \mathrm{g} / \mathrm{kg}$ \\
S. enteritidis* & 0.0001 & 0.022 \\
S. typhosa & 0.0012 & 0.028 \\
Serr. marcescens $\ddagger$ & 0.0003 & 1.052 \\
\hline
\end{tabular}

* Supplied by Dr. Edgar Ribi.

† Supplied by Dr. Marion Webster.

‡ Supplied by Dr. Murray J. Shear. fitting collar; 2) adequate training of animals (usually 1 to 2 days) so that the restraining device and temperature-recording probe are tolerated without anxiety ; 3) acclimatization to the stocks and rectal probes for 1 to 2 hours prior to injection; 4) use of animals of uniform age and weight; and 5) elimination of rabbits with abnormal baseline temperatures. The mean body temperature of 175 trained animals used in this laboratory was $39.2^{\circ} \mathrm{C}$ with a standard deviation of $0.35^{\circ} \mathrm{C}$. Therefore, the temperature range of 38.5 to $39.9^{\circ} \mathrm{C}$ was considered normal. These findings are in satisfactory agreement with those of Lee who reported a mean temperature of $39.6^{\circ} \mathrm{C}$ for unrestrained normal rabbits (10).

In the course of ten experiments 85 normal rabbits that conformed to the above criteria were given a single dose of endotoxin (10 $\mu \mathrm{g}$ per animal). The frequency distribution curves for the fever indices of these animals are shown in Figure 3 , which depicts the range of individual values and the arithmetic means of 85 random samples of four animals taken from this population. The mean fever index for individual animals, as well as for the random samples of four, was $52 \mathrm{~cm}^{2}$. The standard deviation of the indices for individual animals was $12.8 \mathrm{~cm}^{2}$; however, the standard deviation for the means of four-animal samples was $5.9 \mathrm{~cm}^{2}$. It is noteworthy that the scatter of the fever indices was about the same for any point

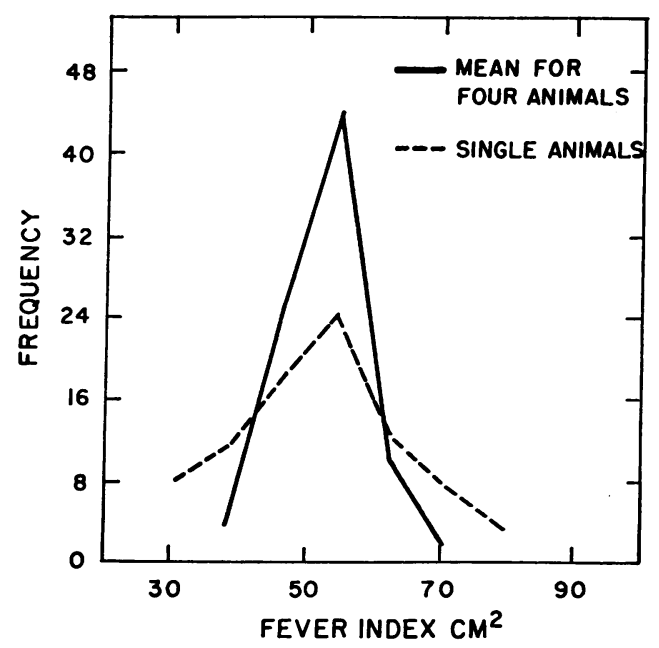

Fig. 3. CoMparison OF THE FREQUENCY DISTRIBUTION CURVES FOR THE FEBRILE RESPONSES OF 85 INDIVIDUAL ANIMALS AND THE ARITHMETIC MEANS OF 85 RANDOM SAMPLES OF FOUR TAKEN FROM THE SAME POPULATION. 
'TABLE II

Febrile response of the rabbil to $20 \mu \mathrm{g}$ of endotoxin

\begin{tabular}{cccccc}
\hline \multicolumn{6}{c}{ Fever index in cm² } \\
\cline { 2 - 6 } $41-50$ & $51-60$ & $61-70$ & $71-80$ & $81-90$ & $91-10$ \\
\hline 44 & 56 & 61 & 71 & 81 & 92 \\
50 & 59 & 62 & 72 & 81 & 95 \\
& 59 & 63 & 72 & 82 & \\
& 59 & 63 & 72 & 84 & \\
& & 63 & 73 & 85 & \\
& & 64 & 75 & 85 & \\
& & 65 & 75 & 86 & \\
& & 65 & 76 & 86 & \\
& & 65 & 76 & 87 & \\
& 66 & 77 & 88 & \\
& 66 & 77 & 88 & \\
& & 66 & 79 & & \\
& & 68 & 80 & & \\
& & 69 & & & \\
& & 70 & & & \\
& & 70 & & &
\end{tabular}

on the linear portion of the dose-response curve. The indices of 48 animals which received $20 \mu \mathrm{g}$ of endotoxin are classified in Table II. The standard deviation of these fever indices was 11.1 $\mathrm{cm}^{2}$. Similarly, the standard deviation for the febrile responses of 15 animals treated with $5 \mu \mathrm{g}$ was $10.2 \mathrm{~cm}^{2}$.

Pyrogenic response of different species to endotoxin. The febrile responses of man, cat, horse and rabbit to a near-threshold dose of endotoxin are presented in Figure 4. In each of these species, except the cat, the minimal pyrogenic dose was determined by measuring febrile responses to graded doses of endotoxin. The smallest dose that

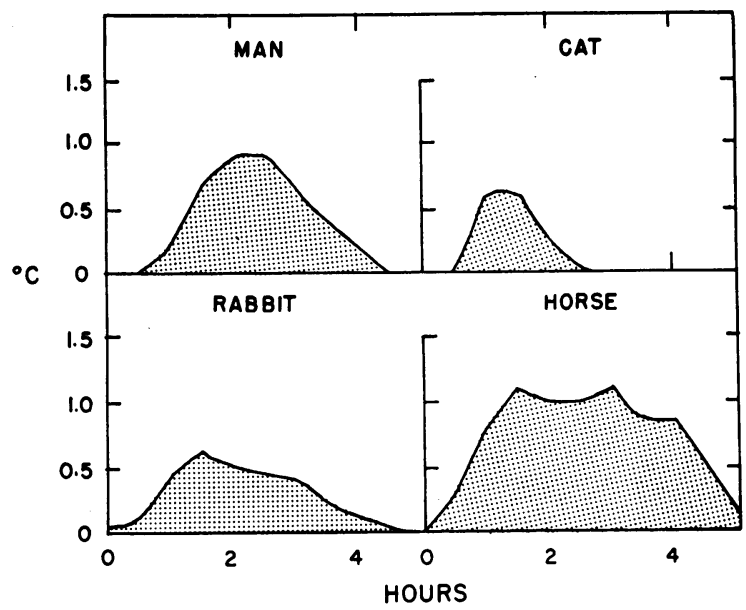

Fig. 4. THE FEBRILE RESPONSES OF FOUR SPECIES TO 0.03 $\mu G$ OF ENDOTOXIN PER KG OF BODY WEIGHT.

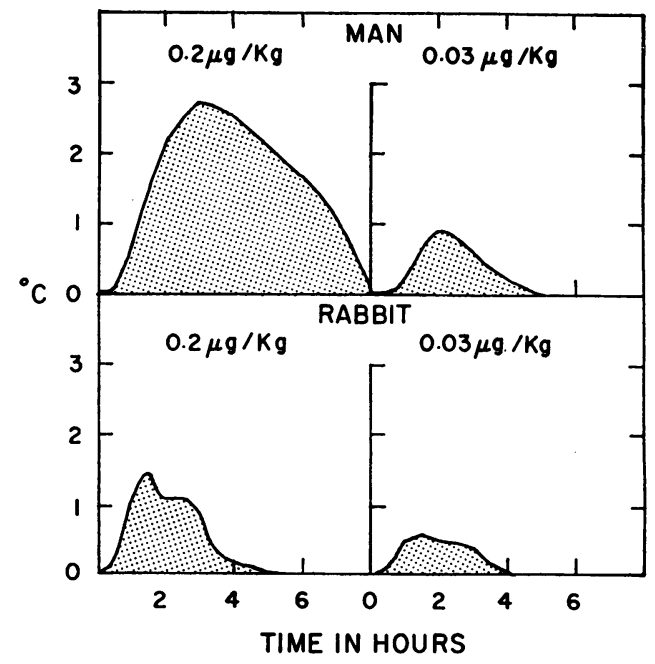

Fig. 5. COMPARISON OF THE FEBRILE RESPONSES OF MAN AND RABBIT TO DIFFERENT DOSE LEVELS OF ENDOTOXIN.

consistently produced at least a $0.5^{\circ} \mathrm{C}$ rise in body temperature was found to be $0.03 \mu \mathrm{g}$ per $\mathrm{kg}$ for each of these species.

Although the thresholds of pyrogenic response for man and rabbit were grossly comparable, the dose-response ratio to larger amounts of endotoxin was different. Figure 5 illustrates the mean febrile responses of two male patients with bronchogenic carcinoma and malignant melanoma, and of four rabbits given $0.2 \mu \mathrm{g}$ of endotoxin per $\mathrm{kg}$. In the rabbit this dose produced a modest febrile reaction, but for the patients it was unexpectedly found to be strongly pyrogenic and very toxic. Both patients responded with profound chilling, fever, nausea, vomiting, diarrhea and hypotension. The latter persisted 36 to 48 hours and was only partially corrected by therapeutic doses of vasopressor agents and blood transfusion. Urinary output was adequate throughout the period of hypotension.

Exploratory experiments with the chimpanzee and dog demonstrated that these species were less sensitive to the Serr. marcescens pyrogen. Two chimpanzees receiving $0.8 \mu \mathrm{g}$ of endotoxin per $\mathrm{kg}$ developed no fever. Four dogs given $1 \mu \mathrm{g}$ per $\mathrm{kg}$ responded with moderate febrile reactions (mean fever index $=22 \mathrm{~cm}^{2}$ ).

\section{DISCUSSION}

The febrile response of individual rabbits to endotoxin, as measured by the fever index, varied 
appreciably even when a number of precautions were taken to minimize variation. Nevertheless, when the febrile responses of groups of four or more animals were averaged, the means were found to be consistent and the dispersion of values was then well within acceptable limits.

The most reliable dose-related measure of the febrile response is the fever index, inasmuch as it represents an objective expression of both height and duration. Wendt, Snell, Goodale and Cranston have shown that in man the fever index is more closely correlated with the dose of endotoxin administered than is the maximum height of the fever; the mean correlation coefficients were 0.817 and 0.501 , respectively. For man, however, the fever index may be a less objective measure than the maximum temperature rise because the superimposition of diurnal variations in body temperature seldom allows the post-injection temperature to return to pre-injection values (11). In contrast, the rabbit has no diurnal variations in body temperature (10), consequently the fever index is an objective measure of the febrile response of this animal. However, for the fever index accurately to represent the febrile response to a given dose, the area under the entire fever curve must be measured. Dawson and Todd considered the fever index just as variable and as poorly correlated with endotoxin dose as the maximum rise in temperature. It is noteworthy, however, that indices were determined by dropping a perpendicular from the highest temperature to the baseline and measuring the enclosed area instead of measuring the total febrile response (12).

The minimal pyrogenic dose is commonly used as a comparative measure of the pyrogenicity of endotoxin preparations. However, in the range of threshold response, doses differing by as much as fivefold to tenfold may produce febrile reactions of similar magnitude. The studies reported here indicate that more precise comparison of endotoxin preparations can be made by determining the minimum dose required to produce a mean fever index of approximately $40 \mathrm{~cm}^{2}$ (assayed in rabbits weighing 2 to $3 \mathrm{~kg}$; fever curves plotted so that 1 hour and $1^{\circ} \mathrm{C}=1 \mathrm{inch}$ ). This response provides a more precise measure of pyrogenicity because it falls on the linear portion of the doseresponse curve.

Knowledge of the relative sensitivity of man and the rabbit to the pyrogenic properties of endotoxin is of obvious importance, since the rabbit is generally used for the testing of biologicals prepared for parenteral therapy. Calculations from the comprehensive studies reported by Seibert (3) show that her patients manifested approximately the same susceptibility as normal rabbits to the pyrogenicity of small doses of crude bacterial filtrates. To produce comparable fevers in man and the rabbit, it was necessary to give 1.0 to $1.5 \mathrm{ml}$ of bacterial filtrate per $\mathrm{kg}$ of body weight (3). The findings reported here provide confirmation for those of Seibert, but suggest that the dose-response curve for man is much steeper than the dose-response curve for the rabbit. It is clear that $0.2 \mu \mathrm{g}$ of endotoxin per $\mathrm{kg}$ was far more toxic for patients than it was for rabbits. This finding is in agreement with those reported by $\mathrm{Co} T \mathrm{Tu}$ and Shrift, who administered large doses of a single pyrogenic solution to man $(11 \mathrm{ml}$ per $\mathrm{kg}$ ) and rabbit $(30 \mathrm{ml}$ per $\mathrm{kg}$ ) and concluded that man was at least three times as sensitive $\left(4.1^{\circ} \mathrm{C}\right.$ rise) as the rabbit $\left(2.2^{\circ} \mathrm{C}\right.$ rise) to bacterial pyrogen (2). Dare and Mogey concluded that the rabbit may be one-third to seven times as susceptible as man to threshold doses of endotoxin (4). However, those studies were carried out in both pyrogen-tolerant rabbits (one-third as susceptible) and in normal animals (seven times as susceptible). Furthermore, different criteria were employed ; uncontrollable chilling was used to determine the threshold dose for man, while the minimal pyrogenic dose was used for the rabbit.

The validity of calculating the dose of endotoxin on the basis of body weight has not been clearly established. Dawson and Todd correlated the pyrogenic response of the rabbit with body weight, but the results were inconclusive (12). In the course of the studies described in this report, one $300 \mathrm{~kg}$ and one $500 \mathrm{~kg}$ horse were injected with equal total doses of endotoxin. The $300 \mathrm{~kg}$ horse responded with a minimal but definite fever (fever index $=12 \mathrm{~cm}^{2}$ ), while the $500 \mathrm{~kg}$ horse developed no fever. However, in another experiment, the dose administered was calculated on the basis of body weight; this time both horses responded with comparable fever.

Endotoxins are macromolecular complexes consisting primarily of polysaccharide and firmly bound lipid with variable amounts of associated 
polypeptides. These substances have been derived from a multitude of different microorganisms by a variety of different procedures. Various workers have employed endotoxin preparations which varied from crude bacterial filtrates to highly purified lipopolysaccharides, but even the purified preparations are considered to be nonhomogeneous by most physicochemical criteria. Nevertheless, all endotoxins are relatively potent pyrogens. The pathogenesis of endotoxin fever has been extensively studied, but the exact physiological mechanisms involved have not been definitely established (1). There is, nevertheless, abundant indirect experimental evidence which suggests that the febrile response is the result of a dual mechanism involving both direct stimulation of the central nervous system by endotoxin and indirect stimulation through the release of endogenous pyrogen $(13,14)$. It is postulated that the exogenous endotoxin damages tissues which in turn release endogenous pyrogen. The latter, along with exogenous endotoxin, stimulates the central nervous system to bring about the total febrile response (15-22). The magnitude of the fever, therefore, would depend, in part at least, upon the extent of the tissue damage and the amount of endogenous pyrogen released. Because of this and abundant other circumstantial evidence, it has been generally accepted that the pyrogenic potency of endotoxin reflects other toxic properties. Although this is a reasonable assumption, there have been no systematic studies that correlate the pyrogenic effects of endotoxin with other toxic host responses. Recent studies in this laboratory have shown that the degradation of endotoxin by plasma enzymes results in the loss of pyrogenicity as well as other toxic properties. Therefore, on the basis of the available information it seems reasonable to conclude that the pyrogenic reaction to endotoxin does, indeed, reflect general toxicity as measured by other host responses.

\section{SUM MARY}

The febrile response of the rabbit has been studied with respect to its use as an assay for endotoxin. Dose-response relationships have been established for a single endotoxin. The mean pyrogenic response of four or more animals, as measured by the fever index, was shown to be highly consistent and to afford a wide range of dose-related measurements. A standard method for comparing the pyrogenic potency of endotoxin preparations is suggested.

Man, cat, horse and the rabbit were found to have the same approximate threshold to pyrogenic stimulation by endotoxin. However, larger doses may be more pyrogenic and more toxic for man than for the rabbit. Both dog and chimpanzee were notably less susceptible to the pyrogenicity of endotoxin than the other species studied.

\section{REFERENCES}

1. Bennett, I. L., Jr., and Cluff, L. E. Bacterial pyrogens. Pharmacol. Rev. 1957, 9, 427.

2. Co Tui, and Shrift, M. H. A tentative test for pyrogen in infusion fluids. Proc. Soc. exp. Biol. (N. Y.) 1942, 49, 320.

3. Seibert, F. B. The cause of many febrile reactions following intravenous injections. Amer. J. Physiol. 1925, 71, 621 .

4. Dare, J. G., and Mogey, G. A. Rabbit responses to human threshold doses of a bacterial pyrogen. J. Pharm. (Lond.) 1954, 6, 325.

5. Wylie, D. W., and Todd, J. P. An examination of the sources and the quantitative methods of testing pyrogen. Quart. J. Pharm. 1948, 21, 240.

6. Perrault, A., and Shear, M. J. The bacterial cell of $S$. marcescens as a source of tumor-necrotizing polysaccharide (abstract). Cancer Res. 1949, 9, 626.

7. Rathgeb, P., and Sylvén, B. Fractionation studies on the tumor-necrotizing agent from Serratia marcescens (Shear's polysaccharide). J. nat. Cancer Inst. 1954, 14, 1099.

8. Beeson, P. B. Tolerance to bacterial pyrogens. I. Factors influencing its development. J. exp. Med. 1947, 86, 29.

9. Landy, M., and Johnson, A. G. Studies on the O antigen of Salmonella typhosa. IV. Endotoxic properties of the purified antigen. Proc. Soc. exp. Biol. (N. Y.) 1955, 90, 57.

10. Lee, R. C. The rectal temperature of the normal rabbit. Amer. J. Physiol. 1939, 125, 521.

11. Wendt, F., Snell, E. S., Goodale, F., Jr., and Cranston, W. I. Measurement of the human febrile response to a bacterial pyrogen. Clin. Sci. 1956, $15,485$.

12. Dawson, M., and Todd, J. P. The assay of bacterial pyrogens. J. Pharm. (Lond.) 1952, 4, 972.

13. Bennett, I. L., Jr., and Keene, W. R. Studies of the febrile response to acute bacterial infection and bacterial pyrogens. Bull. N. Y. Acad. Med. 1956, $32,848$.

14. Bennett, I. L., Jr., Petersdorf, R. G., and Keene, W. R. Pathogenesis of fever: Evidence for di- 
rect cerebral action of bacterial endotoxins. Trans. Ass. Amer. Phycns 1957, 70, 64.

15. Beeson, P. B. Tolerance to bacterial pyrogens. II. Role of the reticulo-endothelial system. J. exp. Med. 1947, 86, 39.

16. Bennett, I. L., Jr., and Beeson, P. B. Studies on the pathogenesis of fever. I. The effect of injection of extracts and suspensions of uninfected rabbit tissues upon the body temperature of normal rabbits. J. exp. Med. 1953, 98, 477.

17. Bennett, I. L., Jr., and Beeson, P. B. Studies on the pathogenesis of fever. II. Characterization of fever-producing substances from polymorphonuclear leukocytes and from the fluid of sterile exudates. J. exp. Med. 1953, 98, 493.

18. Grant, R., and Whalen, W. J. Latency of pyrogen fever. Appearance of a fast-acting pyrogen in the blood of febrile animals and in plasma incubated with bacterial pyrogen. Amer. J. Physiol. 1953, $173,47$.
19. Atkins, E., and Wood, W. B., Jr. Studies on the pathogenesis of fever. I. The presence of transferable pyrogen in the blood stream following the injection of typhoid vaccine. J. exp. Med. 1955, 101, 519.

20. Atkins, E., and Wood, W. B., Jr. Studies in the pathogenesis of fever. II. Identification of an endogenous pyrogen in the blood stream following the injection of typhoid vaccine. J. exp. Med. 1955, 102, 499.

21. King, M. K., and Wood, W. B., Jr. Studies on the pathogenesis of fever. IV. The site of action of leukocytic and circulating endogenous pyrogen. J. exp. Med. 1958, 107, 291.

22. Petersdorf, R. G., Keene, W. R., and Bennett, I. L., $\mathrm{Jr}$. Studies on the pathogenesis of fever. IX. Characteristics of endogenous serum pyrogen and mechanisms governing its release. J. exp. Med. 1957, 106, 787. 